\title{
Sea-Temperature, Breeding and Distribution in Marine Animals.
}

By

By J. H. Orton, D.Sc.

Naturalist in the Plymouth Laboratory.

With 1 Figure and 2 Tables in the Text.

\section{CONTENTS.}

Introduction .

Results of observations on breeding in marine animals of known ages obtained by experiment

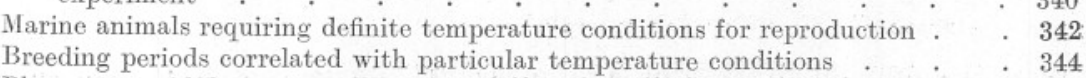

Phenomena of hibernation correlated with temperature . . . . . . 351

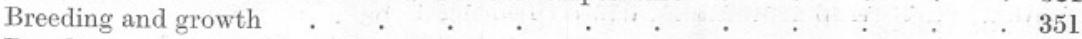

Breeding under stenothermal conditions $\quad . \quad$. . . . . . . . . . . . 353

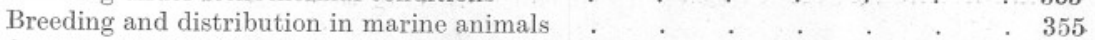

Origination of species by variation of breeding-temperature constants _. . . 357

Physiological constants of a species . . . . . . . . . . . 330

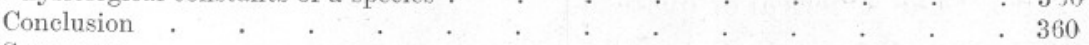

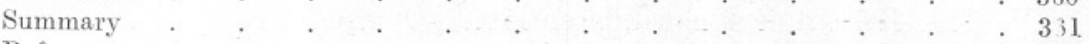

References . . . . . . . . . . . . . . . . . . . . .

\section{INTRODUCTION.}

BREEDING in marine animals has long been recognised in a vague way as being in some degree dependent upon sea-temperature. This attitude is well shown in Lo Bianco's last valuable contribution to our knowledge of the breeding periods of practically the whole fauna of the Gulf of Naples. In the Introduction to this work Lo Bianco (1, p. 531) gives tables of temperature observations for a number of years, but does not attempt to correlate them with the breeding periods observed. There are in the literature some observations of reproduction in particular animals being dependent upon particular temperatures, notably by Schmidt (2); but no attempt has been made, so far as I know, to show in a general way the connexion between breeding and temperature in marine animals. It is clear, however, from the writings of Appellöf that this naturalist had anticipated in his mind some of the results obtained from the experimerital observations described briefly in the following pages and of the deductions made therefrom. It is believed that these experimental observations have afforded a clue which gives an insight into the way in which breeding may be correlated with temperature in a large number of marine animals, but owing to the inadequacies of breeding records and of observations on physical conditions in the sea only a brief survey has 
been atitempted here, and a fuller discussion of the phenomena is reserved for a later work. In the following pages the extrusion of ripe ova, or the feritisability of eggs with subsequent development, is taken as the criterion of breeding.

\section{RESULTS OF OBSERVATIONS ON BREEDING IN MARINE ANIMALS OF KNOWN AGES OBTAINED BY EXPERIMENT.}

In the course of a research on the rate of growth of marine invertebrates, two of the objects of which research were (see Orton, 3, p. 312) -

(1) the determination of the minimum size at which maturity is attained,

(2) the investigation of the rate of growth at different seasons of the year and under different conditions,

results were obtained which pointed to the factor of temperature being of paramount importance in controlling breeding $(3, \mathrm{p} .314)$. The facts which led to this conclusion are as follows:

Experiments on the rate of growth of marine invertebrates were carried out by putting out in the sea at noted times various objects, such as floating rafts, shells and pieces of wood attached to fixed objects. Numerous experiments were made at different times of the year with the object of obtaining information of successive growths. Material was collected from the experimental plots from time to time, and all animals collected were examined fresh with a view to determine the sexual activity of the different animals at known ages. By this means it was found in several different animals belonging to entirely different phyla that quite small individuals or colonies of a very young age were actively reproducing at certain periods suitable to the particular animal for reproduction, but that relatively very large and growing individuals were not reproducing at other periods of the year. For instance, the data obtained with regard to the two sponges, Grantia compressa and Sycon coronatum, may be put shortly as follows :-

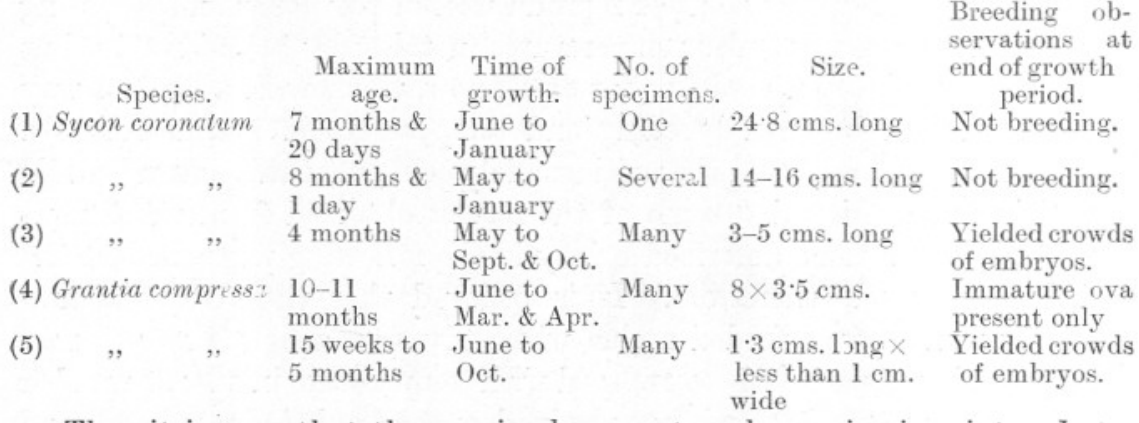

Thus it is seen that these animals grow to a large size in winter, but do not begin to breed unitil April or May. Individua's born in the summer, 
however, rapidly attain maturity, ${ }^{*}$ and in one particular experiment relatively tiny animals were rapidly reproducing at an age less than 4 months, whereas enormous growing individuals of an age 7 to 8 months were not breeding in early spring. I have no doubt that the summer-born individuals may breed twice in the course of a lifetime, once in late summer, and again in the following late spring or early summer $\dagger$ (4, p. 322). Similar phenomena to these have been observed in Leptoclinum gelatinosum and Botryllus violaceus and in other animals. In searching for an explanation of these facts it was observed that the beginning and the end of the breeding period coincided with approximately the same sea-temperature, and since a large growth occurs in these species during the winter the factor of food in determining breeding can be eliminated.t There remains still, however, another important factor-namely, salinity - which may influence breeding. But there is some ground for the view that changes in salinity, at least in the deeper estuaries, are subject to similar fluctuations in summer as in winter, and that, except for periods after heavy rains, estuarine salinities at a given position in the estuary are fairly constant throughout the year. This view is supported by the observations of Mill (5) in the Firth of Forth, of Dickson (6), in the Kent and Essex Estuaries, the mouths of the Schelde and the Weser, and of Karsten (7) and Meyer (8) in the German Bight. $\$$

An important factor in helping to maintain similar salinity conditions in estuaries at different periods of the year is the occurrence of an offshore maximum of salinity in late autumn and winter off Western Europe at about the period of the maximum inflow of fresh water into the sea.|l (See Fig. 1, p. 348.) This problem will be discussed more fully later, but there will necessarily remain some uncertainty about the factor of salinities in estuaries until more detailed observations are available extending over a period of years; and in view of the importance of understanding the conditions of life of estuarine faunas - of which boring animals and young fishes are notable examples-and floras, it is to be hoped that physical investigations of this kind will be undertaken in many different localities. For the present, however, there is good reason for the view that in a

* On July 15th, 1920, tiny Grantia compressa $10 \times 4$ millimetres and Sycon coronatum 8 to $9 \times \mathrm{ca} \cdot 3$ millimetres were collected and examined at once. Fully developed ciliated embryos were found in teasings of even these tiny individuals of both species. I have no doubt whatever that these specimens are young ones born in the summer of 1920 . They cannot therefore be more than three months old, whilst the tiniest ones with embryos I estimate are probably not more than about one month old. (Compare the similar phenomena described on p. 352.)

$\dagger$ An experiment designed to test this point was in progress in the summer of 1914 but was neglected in order to take up temporary fishery work. An account of the lifehistory of Grantia is given by the writer in $3, \mathrm{p} .315$.

\# A review of all the data given here tends to show that there can be no qualitative effect of food.

$\S$ A fuller discussion of the available data will be published shortly in a separate publication on breeding in the European oyster, $O$. edulis.

If See J. von Hann. Lehrbuch der Meteorologie. Leipzig, 1915, p. 356. 
deep estuary such as Plymouth Sound the salinity does not vary greatly throughout the year except after periods of heavy rains, and even at these times it is probable that bottom salinities are not greatly affected. The fact, therefore, that the sponges and other animals mentioned above do not breed when the sea-temperature falls below a certain level points to the paramount importance of temperature in controlling breeding phenomena in these animals. Subsequent investigations on the breeding periods of animals have strengthened the view of the importance of an appropriate temperature and weakened that of the effect of normal changes of salinity in controlling breeding in marine animals in general.

\section{MARINE ANIMALS REQUIRING DEFINITE TEMPERATURE CONDITIONS FOR REPRODUCTION.}

Such a view of the importance of temperature led at once to a variety of suggestions. The first suggestion came from a recollection of the paper by Allen (9) on the breeding periods of the mackerel (Scomber scomber), which it was recollected showed earlier breeding periods the further south the region of habitat, and later ones the more northern. These were investigated, and the conclusion arrived at that the mackerel does not spawn throughout its geographical range when surface temperatures are less than close on $12^{\circ}-13^{\circ} \mathrm{C}$. The details of this investigation will be given later. This result gave a spurt to apply the principle to all fishes, but in reviewing the literature with me, my co-worker, Mr. R. S. Clark, drew my attention to Schmidt's work on the species of East Atlantic Gadoids(1), all of which Schmidt found to spawn at fairly definite temperatures and within fairly narrow limits. This valuable paper was unknown to me at the time, and afforded an additional stimulus. Later I was also indebted to Clark for drawing my attention to the observations of Nilsson on the mackerel, which confirmed my earlier view of the minimum temperature at which this fish spawns. Nilsson (10) found that off the Swedish coast mackerel eggs were only taken between the temperatures of $57^{\circ} \cdot 92 \mathrm{~F}$. $\left(14^{\circ} \cdot 4 \mathrm{C}\right.$.) and $59^{\circ} \cdot 72 \mathrm{~F}$. ( $15^{\circ} \cdot 4 \mathrm{C}$.) from July 1-6 in 1911, and Nilsson makes the significant remark that "It is, moreover, highly probable, as several writers have already suggested, that the temperature here exerts a considerable influence, and that the mackerel do not discharge their genital products until the water has reached a certain degree of warmth." Following up this success, the breeding records of all marine animals were collected so far as they could be obtained and were examined; but it was soon found that in many cases records were too incomplete, or were not recorded in such a way as to enable one to extract the fundamental phenomena, or were not accompanied by sufficient data to enable one to correlate temperature with 
the onset of breeding in bulk. It waz uherefore decided to examine thoroughly what is known of breeding conditions in a few well-known animals. The European oyster $(O$. edulis) was quickly chosen as one for which a good deal of information might be available. A review of the literature bearing on the breeding conditions of this animal throughout its geographical range at once showed the importance authoritative naturalists attached to temperature conditions in the control of breeding in this mollusc. An exhaustive investigation of the degree of correlation between breeding and temperature throughout the geographical distribution of this animal was therefore undertaken and has now been completed. The results will shortly be published separately in detail: It was found that, as in the case of the mackerel, breeding begins earlier in the more southern and warmer regions, e.g. Italy, and later in the more northern and colder localities, as the more open oyster pools of Norway, and at intermediate times on the French, Dutch and English beds. Throughout its range this mollusc appears to begin to breed at a temperature of about $15^{\circ}-16^{\circ} \mathrm{C}$. in varying salinities from about $25^{\circ} \%$ to as high as $36^{\circ} \%$ or more in the Gulf of Naples, and continues to breed so long as the temperature remains above this figure, so that in the warmer situations there is a longer breeding period than in the colder ones. This important generalisation, namely, that breeding continues in this - and indeed in other-species while the temperature remains above a certain figure, it will be seen, agrees with that deduced from the observations on the sponges mentioned above, and further points to temperature as the main factor controlling breeding, always, of course, assuming normal biological conditions. This generalisation, as applied to the breeding period of a large number of marine animals, is discussed on pages 344-350. (See also Table II, p. 350.)

In the course of the investigation of the breeding conditions in this oyster the interesting record was found $(11, \mathrm{p} .1)$ of the occurrence of the Copepod, Paracartia grani-which is a species bclonging to a tropical genus - in the Espevik and Selo oyster ponds in Norway, where in summer tropical temperature conditions obtain (Friele, 12, p. 188). This crustacean, according to Sars, is an undescribed species whose allies are not found nearer to Norway than the West Coast of Africa, and whose nearest ally is a species living in New Guinea; it is not found in neighbouring fjords, and is considered by Sars as a relict of a warmer age. The Espevik and Selo ponds are amongst the warmest of the Norwegian oyster pools, and in the former a temperature as high as $35^{\circ} \mathrm{C}$. may be attained in some years. The breeding period of this interesting form is not given, but its determination will be awaited with much interest.

Additional records of the importance of temperature as a controlling 
factor are given by Appellöf (13, p. 556, footnote) of Mysis relicta, an Arctic survival form which occurs in the depths of the cold North German lakes during summer and migrates landwards during autumn and winter, beginning to breed chiefly at a temperature of $3^{\circ} \mathrm{C}$. Pontoporeia affinis is another similar form which reproduces in winter at between $0^{\circ}$ and $7^{\circ} \mathrm{C}$. Appellöf also makes the following suggestion, which is significant for the purposes of this research: "It will be interesting to find out whether the boreal forms which penetrate into boreo-arctic areas with high temperatures for a short portion of the year have a short period of reproduction there, seeing that farther south their reproduction is known to extend over several months." Semper (14, p. 428) quotes Brauer's observations on a species of freshwater form Cheirocephalus, which, whilst kept in water at a temperature of $19^{\circ} \mathrm{C}$., exhibited no signs of sexual maturity, but which in water below $11^{\circ} \mathrm{C}$. developed sexual functions in two days. In this case temperature would appear to be unquestionably the sole factor determining sexual activity.

As an illustration of the importance of temperature in breeding in animals whose environmental conditions are relatively casily controlled, the investigations of Dendy and Elkington (15) on the grain insects Calandra oryzce, C. granaria and Rhizopertha dominica may be mentioned. Dendy and Elkington found the lower limit for breeding for the species of Calandra at about $65^{\circ} \mathrm{F}$. $\left(18.33^{\circ} \mathrm{C}\right.$.), and at about $70^{\circ} \mathrm{F}$. $\left(21 \cdot 11^{\circ} \mathrm{C}\right.$.) for Rhizopertha. No doubt other cases could be given, but enough has been cited to demonstrate the great importance of temperasure as a factor controlling breeding in marine and some other anima's.

\section{BREEDING PERIODS CORRELATED WTTH PARTICULAR TEMPERATURE CONDITIONS.}

The breeding periods of animals at Naples have been investigated and collected by Lo Bianco (1). At Plymouth similar records have been collected and published in the "Plymouth Marine Invertebrate Fauna ". (16), and I have been able to obtain, by the kindness of the Council of the Millport Marine Biological Station and Mr. R. Elmhirst, the unpublished breeding records for the locality of the River Clyde.

From the examination of these breeding records and from a consideration of the general phenomena of breeding in marine animals, namely, the periodicity, the inciderce ard the extent of breeding in different localitios, it would seem from the results described above that most animals under normal conditions begin to breed either at a definite temperature, which is a physiological constant for the species, or at a definite temperature change, namely, at either the maximum or the minimum temperature of the locality. 
Further, in a particular locality it would appear that many animals, of which the oyster may serve as a type, continue to breed so long as the temperature remains above a certain figure; and again, of others which continue to breed so long as the temperature remains below a certain figure, so that in these cases the breeding period can be expressed on the average in terms of temperature or in terms of homothermal epochs on the sea-temperature curve for that locality. In different localities or latitudes a particular species may be a winter breeder in the warmer situations and a summer breeder in the colder ones (see p. 351), indicating that in this type breeding may be limited by maximum and minimum temperatures. Yet a further type of breeding is furnished by those animals which reproduce in a particular locality all the year round. It is an interesting fact that these latter forms have generally a wide distribution, such as Ciona intestinalis, which breeds all the year round at Naples (Lo Bianco, 1, p. 658), and very nearly, if not quite, all the year round at Plymouth. Patella vulgata, which has also a very wide distribution, breeds at Plymouth at about and after the attainment of the maximum sea-temperature and at about and after the arrival of the minimum. At the latter period tiny individuals less than $1 \mathrm{~cm}$. long (Orton, 17, p. 373), with gonads not bigger than a few millimetres, are in possession of fully developed and active sperm ; corresponding observations on tiny specimens in August have not yet been made.

The deduction that breeding in a species is determined by temperature has been applied to several animals for which only isolated breeding records have been made. For instance, Styelopsis (Dendrodoa) grossularia is recorded in the Plymouth Marine Fauna List', 1904, as breeding in May and October. Monthly observations made during 1919-1920, except for July, * have filled in all the gaps and extended the breeding period from early April to early December. This breeding period may be compared with that of Aplysia punctata, records for which occur from April to October (see "Plymouth Invertebrate Fauna," p. 277), and also those given on page 350. Many other gaps in the breeding periods of animals have been filled in or partially filled in and confidence obtained in predicting the extent of a particular breeding period when some indication is given of the temperature range of the species for breeding. Care must be taken, however, to take into consideration the method of spawning and the rate of growth in a species. Thus animals which extrude all their genital products at once, such as some of the Chitons and some Teleosts, may have one or more sharply defined breeding periods; but the oyster is an example of an animal which extrudes all its ova at once and continues to produce sexual products (see Hoek, 18,

* Tadpoles of this species have been obtained in numbers in July, 1920. 
pp. 219, 221). The determination, however, of the normal breeding period of an animal is rendered more difficult from the almost general absence in the literature of the year of the breeding observations, for the temperature variations from the mean which occur over a long period will result in the lengthening out of the normal breeding period at each end in any animal which can be shown to be influenced by temperature and is closely observed from year to year. This lengthening out of the breeding period will be specially marked in animals which attain maturity in a few weeks or months. (See p. 352.) In all breeding observations, therefore, it is necessary to connote the year of observation as well as the month and date of month and locality.

Temperature observations in estuarine situations require special study, and steps are being taken to instal in a suitable situation for obtaining the kind of information required a continuous self-recording thermometer. It has not been possible to obtain even continuous daily readings at all the situations where a knowledge of the temperature variation is desirable, but fortunately observations are available for the Promenade Pier, Plymouth, where temperatures are taken daily at about 10 a.m. at a depth of 1 fathom in a position about 100 yards from the shore, where there is about 14 feet of water at low-water springs and a fair tidal current. Monthly means for the years 1912-19* (19) are given in Table I, p. 347, along with monthly means of the surface temperature off Prawle Point given by Gee (20) for the years 1904-13 for latitude ca. $50^{\circ} 08^{\prime} \mathrm{N}$., $3^{\circ} 49^{\prime} \mathrm{W}$., the nearest position to Plymouth for which figures are available. The monthly means of salinity at this station are also given along with those of rainfall, hours of sunshine and air temperature at Plymouth (21). It is deeply regretted that no observations are available on the salinities in Plymouth Sound, but a few surface salinity observations given by Matthews (22) for a position about $\frac{1}{2}$ mile from the lighthouse outside Plymouth Breakwater are added. The means given in Table $\mathrm{I}$ have been plotted to give the curves shown in Fig. 1, p. 348, except that weekly means instead of monthly means have been used to show the seasonal variation in temperature of the sea in Plymouth Sound as represented by observations off the Promenade Pier, Plymouth. An examination of the whole table and the curves in Fig. 1, p. 348, will show at once an important general fact in the relation between estuarine and off-shore sea-temperatures first shown by Mill (5a), namely, that at two periods of the year, at about April and Sept.-Oct., estuarine and off-shore seatemperatures are equal, and that temperatures inshore are lower in winter but higher in summer than off-shore. In a deep estuary such as

* I am much indebted to the Plymouth Borough Meteorologist, Mr. H. V. Prigg, for supplying detailed information of these observations. 
Table I, giving mean monthly air-and sea-temperatures (in degrees Centigrade) and salinities at and off Plymouth and monthly means of hours of sunshine and rainfall at Plymouth.

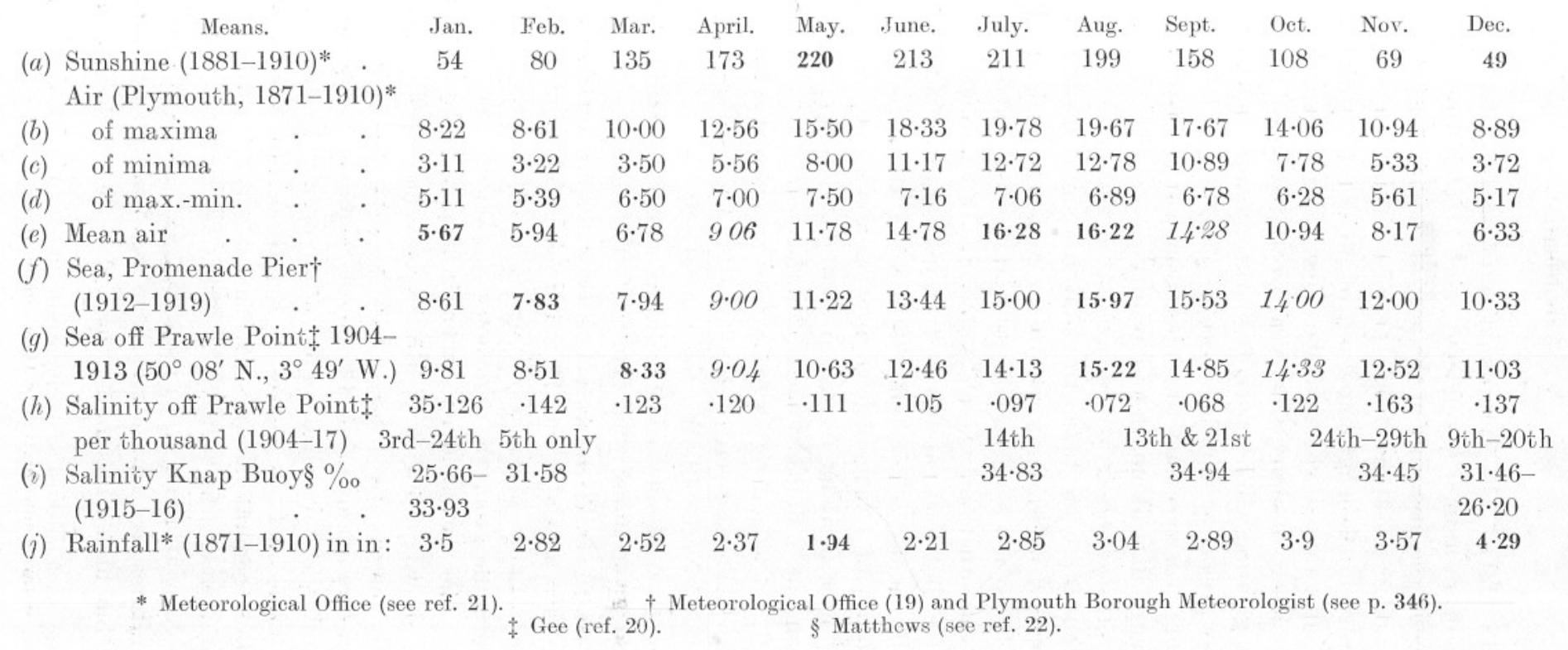




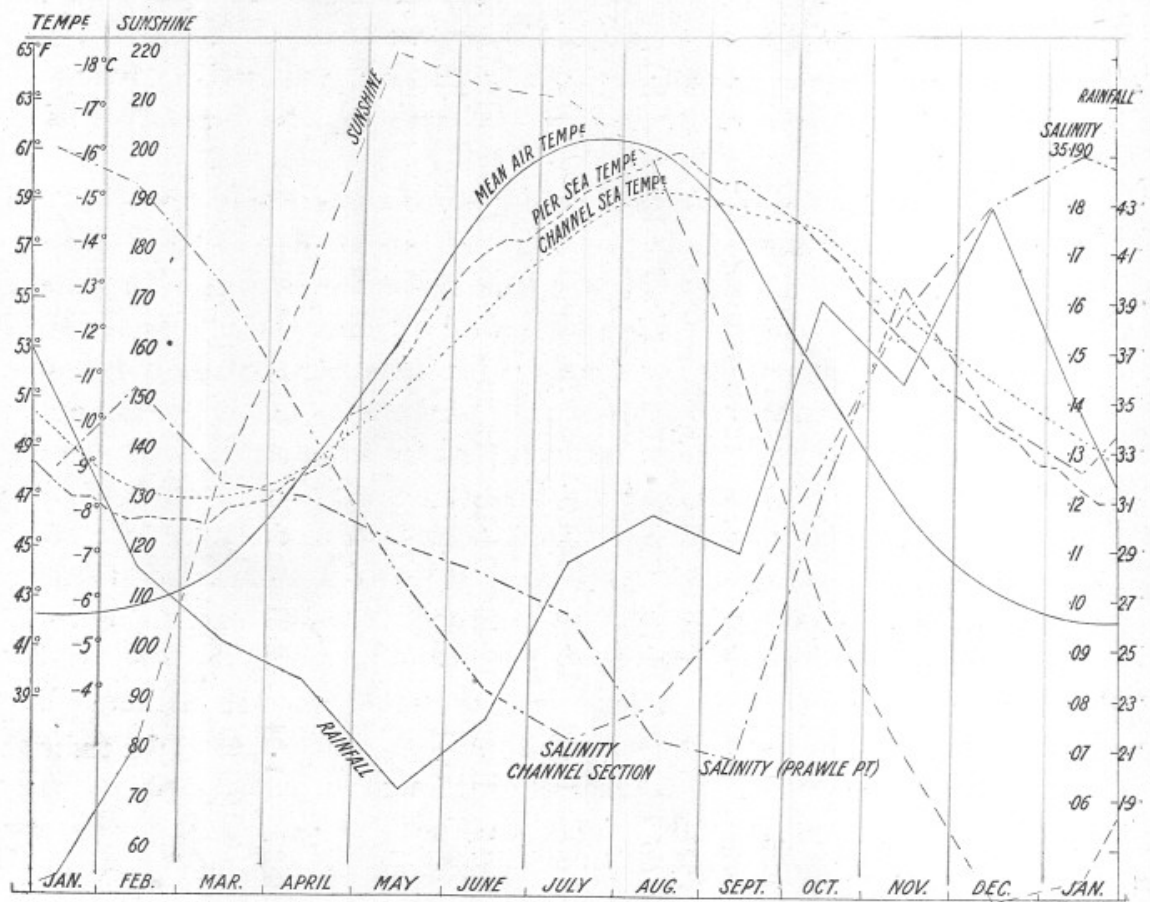

FIG. 1.-Curves of seasonal variation in some important meteorological and physical conditions which contribute to the seasonal variation in temperature and salinity in the waters of Plymouth Sound. The curves are derived from the monthly means given in Table I except that for temperature observations of the sea at a depth of 1 fathom off the Promenade Pier, Plymouth, which is plotted from weekly means.

These curves bring out the following facts for the Plymouth district :-

(a) The coincidence of mean air, mean Pier and mean Channel seatemperatures in April, and of the two latter means in SeptemberOctober.

(b) The rise of the mean air above the mean sea-temperature in April, and its fall below the mean sea-temperature in AugustSeptember.

(c) The successive lag on the curve of duration of sunshine of the curves of mean air, mean Pier and mean surface Channel sea-temperatures respectively.

(d) A maximum Channel salinity approximately coincident with the period of maximum rainfall.

(e) A maximum duration of sunshine coincident in May with a minimum amount of rainfall, and a general inverse relation between the duration of sunshine and the amount of rainfall. 
Plymouth Sound this difference is not so well marked as in shallower estuaries. Another important point is that the mean air-temperaure begins to rise above the off-shore sea-temperature also about April, and falls below again about September, as Dickson (6b) and Helland-Hansen and Nansen (23) have shown to be the case for the region of the East Atlantic.

Corresponding with this it is found that shallow water takes on a higher temperature than deeper water from about March-April and a lower temperature than deeper water from about September. Thus the temperature variations in the exact locality from which animals are obtained must be carefully considered; for instance, animals living on the shore or near high-water mark will exist under higher mean temperature conditions than those in deeper water from April until about September, when lower temperature conditions will occur. Thus, if the breeding periods of shallow water inhabitants are correlated with the Promenade Pier mean temperatures only, a certain amount of skewwhich can be accounted for-will be observed. Owing to the fact that continuous temperature records in shallow water have not yet been made. at Plymouth it has been considered advisable not to attempt at present to give any exact temperatures at which breeding begins in particular species in this district, although a good idea of the figures within fairly narrow limits has been obtained and can be deduced from the Pier temperatures, which can be considered reliable. A few examples of breeding records are given in the following list-as a sample-of animals which breed in the period between approximately homothermal epochs on the sea-temperature eurve.* (See Table II, p. 350.) Approximately homothermal epochs on the mean temperature curve for records at the Promenade Pier are seen to be as follows: (1) end of March and end of January ; (2) end of April and middle of December ; (3) end of May and beginning of November ; (4) beginning of July and beginning of October. In using this list it is important to bear in mind the variation in temperature conditions with locality mentioned above, as well as the possible overlap of breeding seasons from the mean due to temperature variation from the mean over a number of years, and the possible incompleteness of the records in a few cases. The months in which filling-in observations have been made by the writer are printed in italics. The habitats are taken mainly

* In view of the economic importance of the marine boring Lamellibranchs, it is worth while noting here that C. P. Sigerfors (Bull: Bureau of Fish: U.S.A., Vol. xxvii, p. 196) found that Xylotrya gouldi and Teredo dilatata were breeding at Beaufort, U.S.A., from May to August and probably later in the summer, an observation indicating that these species also breed between homothermous epochs. The breeding periods of the species of Teredo infesting British waters are not known, but it would appear to be a reasonable deduction from records in my possession that $T$. norvegica (?) breeds at Plymouth between the period about June-October. 
from the Plymouth Fauna List (l.c.), supplemented in a few cases with observations of my own.

\title{
Table II, illustrating continuous breeding at Plymouth between approximately homothermal epochs.
}

\author{
Species. Habitat. Breeding Period.
}

\begin{abstract}
Bougainvillea ramosa*. L.W. to ca. $30 \mathrm{fms}$. April,May,Aug.,Sept.,Oct. Clytia Johnstoni* . „ „ Mar., April, May, July, Aug., Sept., Oct,

Gonothyrœa loveni . Chiefly low-water mark. Mar., April, Sept., Oct., Nov.

Obelia geniculata* . Chiefly low-water mark. March-Sept., Oct., Ncv † $^{*}$ Sycon coronatum . Chiefly at, but also below May, June, July, Aug., L.W. Oct., Nov. +
\end{abstract}

Grantia compressa . Chiefly between tide- $\uparrow$ April, May, June, July, marks, but also on float- Aug., Oct., Nov.广 ing objects.

Bunodes gemmaceaई . Chiefly between tide- March, April, July, Sept. marks.

Actinia equina§ . . ,

Amphiura elegansई . L.W.-20 fms.

Echinus miliaris . L.W.-35 fms., chiefly between tide-marks.

Jan.-Aug., Sept., Oct., Nov., Dec.

April, May-Sept.

Ascidiella aspersa . Chiefly at and below

March, April, May, June, July, end of Aug. Tarch, April, May, June, L.W. and R. Yealm July, Sept., Oct., Nov., bed.

Ciona intestinalis : Chiefly just below L.W. A A May, June, July, and on floating objects Aug., Sept., Oct., Nov. in docks.

Clavellina lepadiformis Chiefly at and below May, June, July, Sept. L.W., also 10-15 fms.

Cardium edule $\|$. R. Yealm bed.

Ostrea edulis

R. Yealm and the Hamoaze, 0 to a few fms.
March, April, May, June, July, Oct.

June, $\boldsymbol{\top} \boldsymbol{J}^{7} y, \uparrow$ Aug., Sept.

* In the case of Clytia, Bougainvillea and Obzlia the breeding record, when given by the writer, is of medusæ extruded, but may only refer to the occurrence of gonophores in other cases. This, however, is probably sufficient. In an undescribed experiment carried out in October, 1919, on the rearing of medusæ in the sea, I obtained a Clytia. medusa bearing gonads at an age of 10 days from the time of liberation from the gonophore. Wright (see Hincks, British Hydroid Zoophytes, p. 143), however, obtained the same medusa with gonophores in a few days and a young hydroid within a week of the liberation of the parent medusa. The medusa of Clytia may therefore be regarded as little more than a free-swimming gonad. In the other cases little is known of the length of time required in the sea for the development of the gonad, but $\mathrm{E}$. T. Browne has informed me in conversation that they develop within a few weeks when reared even in the laboratory. In the sea the period is probably shorter. This limitation of the records must, however, be borne in mind.

$\dagger 1913 . \quad \$ 1914 . \quad \$$ With young. $\quad \dagger \dagger$ With gonophores 1919.

II Ripe eggs and sperm. Tais species is also known to have full gonads throughout the summer, and fertilised eggs were obtained in July and October.

T Ripe sperm and white ciliated embryos in June, and "black spat," i.e. shelled veligers in early July, 1920. 


\section{PHENOMENA OF HIBERNATION CORRELATED WTTH TEMPERATURE.}

Phenomena similar to those of breeding are observable in forms which hibernate. The Ascidian Clavellina lepadiformis has been carefully watched at the time of its appearance in spring about the end of May and its disappearance in autumn about the end of October. As these are approximately homothermal epochs, there is every ground for concluding that the phenomena are purely temperature effects, since both old and young colonies have been observed to go inco hibernation. This species awakens in the spring, grows rapidly, and begins to breed within a few weeks of its first appearance. Breeding has been followed in this species into September, and is believed to occur practically up to the time of hibernation, as occurs in Morchellium argus, which behaves similarly to Clavellina. In these two forms breeding and growth appear to be especially closely connected.

Some hydroids also hibernate in winter at Plymouth and breed at and about summer, as Plumularia pinnata, Antennularia antennina, ${ }^{*}$ and probably also Antennularia ramosa and Bougainvillea ramosa. It is an interesting fact that the two species of Antennularia and Bougainvillea are winter breeders at Naples (Lo Bianco, 1, p. 539). It is not unreasonable to expect that hibernation of these latter forms occurs at Naples in summer, and if this supposition is confirmed it will be possible to work out for these species the temperature range for breeding and the upper and lower temperatures at which hibernation occurs (see a'so p. 359).

\section{BREEDING AND GROWTH.}

The observations noted above on the occurrence of tiny breeding specimens in a suitable temperature medium and of relatively large specimens not breeding in unsuitable temperature conditions from which the factors of food and apparently salinity may be eliminated afford some insight into the different conditions necessary for growth and breeding, and for growth during breeding.- Animals such as (a) Grantia compressa, Sycon coronatum, Leptoclinum gelatinosum and Botryllus violaceus grow to a large size during the non-breeding period; other

* The temperature phenomena of hibernation provoke a suggestion with regard to the experiments made by Drew and De Morgan on the restitution bodies of this species (Journ. Mar. Biol. Assoc., Vol. X, No. 3, p. 440). The experiments were performed in winter under uniform low temperature conditions (see p. 444). Restitution bodies were formed, but no polyps developed. Wilson (Journal of Exp. Zool., 1911) obtained polyps from restitution bodies, but his experiments were carried out in July. I therefore make the suggestion that if these experiments were repeated under temperature conditions which are more favourable for the physiological operations of the species more success might be obtained.

NEW SERIES. - VOL. XII. NO. 2. JULY, 1920. 
animals, such as (b) Clavellina, Morchellium, Plumularia and other forms hibernate during the non-breeding period; whilst others, as $(c)$ Cardium edule, ${ }^{*}$ and probably other bivalve molluses, do not grow much during the non-breeding period. The animals in category $(a)$ appear to have alternating periods mainly of growth and mainly of breeding, and the size attained in these forms will depend mainly upon the relative lengths of the breeding and the non-breeding periods in a particular locality. In category $(b)$ growth and breeding is almost contemporaneous, as it also is in category $(c)$, except probably for a short period of diminished growth, between each end of the breeding and resting periods, and in both cases it would seem that size in a particular locality will depend, among other factors, on the relative lengths of the growing and breeding periods. In the same species, therefore, size will vary, among other factors, inversely as the length of the breeding period. There are indications, however, that in all animals born into suitable breeding conditions gonad development occurs very early during the period of growth and at the expense of increase in size. Thus, in the instances quoted above tiny Grantia and Sycon of from 1 to a few cms. were reproducing in a lively manner in autumn ; tiny Patella of about $1 \mathrm{~cm}$. in length were sexually mature in winter; similarly quite small Clavellina and tiny colonies of Leptoclinum have been found extruding tadpoles; and Cardium and Crepidula are mature in less than a year; Obelia settles as a planula and grows into colonies which give off medusæ in a maximum period of 3 weeks during summer. Recently I have obtained small specimens of Conchoderma virgatum - some of which were extruding larvæ - from the bottom of a ship which was loaded in the River La Plata in fresh water and took 5 weeks to cross the Atlantic. The maximum age of these specimens was therefore 5 weeks, and a small proportion were already sexually mature. Hornell (24) obtained tiny pearl oysters $26 \frac{1}{2} \times 25 \frac{1}{2} \times$ $9 \mathrm{mms}$. of an age not more than $3 \frac{1}{2}$ months with ripe sexual products ready to be shed, and I have confidence in predicting that young specimens of the European oyster will be found to be sexually mature in the summer in which they are spawned in those situations where high temperature conditions obtain for a few months. Many other instances could be given of the attainment of sexual maturity at a very early age $\dagger$ where animals are born into suitable temperature conditions which

* I have obtained definite information by experiment that Cardium edule practically ceases to grow during the colder months.

+ Tiny Echinus miliaris have frequently been found by workers in this Laboratory to be functionally mature. In an investigation of the sexual habits of this species (Journ. Mar. Biol. Assoc., Vol. X, No. 2, p. 254, 1914) I recorded size as well as state of growth, and find among the records ripe males and females in May at a size of 12 and $13 \mathrm{~mm}$. in diameter. The ages of these are not actually known, but I should say they are certainly under a year judging from evidence in my possession relating to other specimens of this specics. 
continue for some time. In the tropics this phenomenon would be expected, but it also occurs, as I have shown above, in temperate $r$ gions.

The instances of early maturity given in this paragraph give some insight into the nature of the influences which affect the pre-breeding period in some marine anima!s. It is clear that when animals are born into breeding-temperature conditions-other things being normal - the sexual cells mature in a very short space of time; but in larger animals than these, which produce enormous quantities of eggs, different conditions are known to obtain. For instance, Turner, ${ }^{*}$ in investigating the "Seasonal Cycle in the Perch (Perca flavescens) Spermary," found that "the beginning of the period of spermatogenesis and of the sudden increase in size of the testis is contemporaneous with the beginning of the seasonal reduction of the temperature of the water in which the perch is found," and that "the expulsion of the spermatozoa occurs at the same time as the seasonal rise in the temperature of the water" (l.c., p. 704). It is true that this fish is a freshwater form, and may therefore be receptive to influences in a manner different from marine fishes, $\uparrow$ but the phenomena are suggestive and indicate a direcuion for further researches. This question is discussed a licile more fully in the paper on the oyster referred to, but there is not enough information available to discuss the problem fully.

\section{BREEDING UNDER STENOTHERMAL CONDITIONS.}

It follows from these observations that in those parts of the sea where uemperature conditions are constant or nearly constant, and where biological conditions do not vary much, that marine animals will breed continuously. This is apparently the case in the tropics, since Semper states $(14$, p. 110$)$, with reference to the Philippines, that "What was far more striking in these islands was the total absence of all periodicity in the life of the sea-animals, particularly the Invertebrata. Among these I could not detect a single species of which I could not at all seasons find fully grown specimens, young ones and freshly deposited eggs." At

* Journal of Morphology, Vol. 32, No. 3, Sept., 1919, p. 704.

$\uparrow$ Since the above was written Dr. Hjort has drawn my attention to the phenomena of seasonal variation in the gonad of herring taken off the Norwegian coast and recordcd by himself (Pub: de Circonstance, No. 53, 1910), and E. Lea (Pub: de Circonstance, No. 66, 1913). The Table given by Lea (l.c., p. 24) is highly instructive and shows, as Dr. Hjort stated, that gonad development begins in these forms in the summer at about the period of maximum temperatures in the upper layers of water down to a depth of about 50 metres (see Hjort, 25, fig. 509, p. 709) and attains a maximum of development in the period February-April when spawning occurs. At this period minimum temper tures occur down to a depth of about 50 metres (see Hjort, 25, fig. 509). If the sampls $\mathrm{s}$ given by Lea above can be shown to belong to the same community or stock of herringr, then it would appear that this fish-and probably many others-has its sexual activity controlled by temperature conditions in the $\sim \mathrm{re}$ way as Turner has shown to be the case in the yellow perch. 
the Philippines, Semper states that the surface temperature does not vary more than $2^{\circ} \mathrm{C}$. throughout the year. This phenomenon appears to be generally recognised for the tropics, but it would appear that definite systematic work on the breeding and rate of growth throughout the year of a large number of animals in the tropics would still be very useful.

Othor homothermal or stenothermal regions are the deeper parts of the sea and, to some extent, the polar regions. Systematic records of breeding of deep-sea animals may not be available for some time, but it would be well worth while recording the sexual condition of all animals taken from these regions. There are, indeed, some indications that breeding is continuous in these regions, since Hjort (25, p. 739) shows that many most interesting oceanic fishes are sexually mature at the minute size of only a few centimetres (Figs. 526, 529). Remarking on the possible periodicity of breeding in oceanic fishes, Hjort states that "the scarcity of fish eggs and the abundance of pelagic fish fry might appear to indicate a continuous production of rapidly hatching eggs, the larval and post-larval stages being of much longer duration, but a study of the ovaries of the adult fishes does not favour this supposition. In Cyclothone, for instance, the eggs seem to be equally developed in every portion of the ovary, and to ripen throughout the entire length of the ovary at the same time. During our cruise the ovaries were found to be ripest at Stations 53 and 64 on the southern section."

It is almost superfluous to point out that these facts do not negative the possibility that breeding may occur all the year round in deep-sea fishes; and, indeed, the same writer points out (l.c., p. 741) that "we are ignorant as to how often these small fishes reproduce their kind during the year," and (l.c., p. 738) that "it is quite evident that a short voyage in a steamer passing over enormous stretches of ocean in the course of a few days offers no opportunity of studying the conditions of propagation all the year round. I can only point out how desirable it is that the Atlantic should be examined at all seasons of the year, for only by this means can the conditions be fully understood." There can be no doubt that an oceanographical expedition to the Atlantic in winter would yield most valuable biological knowledge, providing work could be done. The fact, however, that minute fishes are mature in the deeper waters of the ocean strongly reminds one of the tiny invertebrate young which have grown and matured under temperature conditions suitable for breeding.

In the polar regions apparently examination of fresh material in bulk for breeding conditions is hardly practicable; but Murray and Chun have directed attention to the great prolificness of life in polar waters, and to the fact that several generations of a species appear to live side 
by side. Murray and Loeb, however, have both suggested that an explanation of these phenomena may be found in the greatly retarded rate of growth which it is postulated must occur in these low temperatures. It has to be admitited that there is nearly everything in favour of this view, but it may be observid that experiments on the effect of temperature on rate of development have been carried out apparently entirely on animals whose optimum temperaure for growth is well above $0^{\circ} \mathrm{C}$., consequently results obtained by reducing the temperature are based on abnormal conditions for the particular animal, and it may be doubted whether the abnormal results from one or a series of animals are sufficient to prove that they will hold for animals in which these abnormal conditions are normal. And, indeed, an examination of plankton made in the coldest period, i.e. February, at this station end compared with plankton at any other period of the year, gives anything but the impression of a general slowing up of development, and shows that reproduction is as active in general as probably at any other time of the year. However this may be, definite information on rate of growth in the polar regions might easily be obtained by buoying or sinking and anchoring different objects for marine animals to settle on and grow. Apart from these considerations, however, the alternation of long periods of daylight with long periods of darkness must alter the biological conditions profoundly, at least in the upper layers of the waters in the polar regions, and it may be doubted whether any form of marine life is independent of such a fundamental change whatever the remaining physical conditions of the habitat may be. Nevertheless it is to be expected that during constant biological conditions breeding will be found to be continuous in the polar regions. Hence it is well worth while to record the sexual condition of all animals taken in the polar regions.

\section{BREEDING AND DISTRIBUTION IN MARINE ANIMALS.}

It was quite early recognised that if temperature is of importance in the breeding of marine animals it must also be of immense importance in affecting their geographical distribution. Sea-temperature has long been regarded of importance in limiting distribution, and many writers have attempted to show the correlation, but only a few can be mentioned here. Hjort (25, and especially Chapter VII) and Appellöf (13) give numerous instances of the limitation of the geographical distribution of marine animals by temperature conditions, but it is only possible to quote here the general observations of these naturalists. Hjort defines the limits of the Arctic and boreal faunas of the Atlantic in terms of temperature (l.c., p. 637), and again (p. 777) of the boreal 
and warm-water forms. Appellöf al o st tes (13, p. 526): "Generally speaking, the limits between a littoral and non-littoral zone seem to be less clearly defined in the arctic than in the boreal region. The reason for this is obvious, if we remember that temperature largely controls distribution.* In high arctic latifudes the difference in temperature between deep and shallow waters is inconsiderable compared with that at corresponding depths in boreal areas. As a result, the forms find favourable conditions of existence so far as temperature is concerned at very different depths, and the vertical distribution of most of the arctic forms is far more extensive than that of boreal forms" ; and again (l.c., p. 557), "it is not so much the depth as the temperature which regulates the distribution of animals." $\dagger$ Moreover, Appellöf is fully aware of the importance of suitable temperatures for reproduction, for he states (l.c., p. 556) "That many of our littoral animals are able to live in boreo-arctic areas at a low temperature depends upon their finding the conditions necessary for reproduction, namely, higher temperatures during a portion of the year" ; and again, in a footnote to page 556: "It will be inceresting to find out whether the boreal forms which penetrate into boreo-arcic areas with high tem. peratures for a short period of the year have a short period of reproduction there, seeing that farther south their reproduction is known to extend over several months." In my investigations of the breeding period of the oyster throughout its geographical range I have been able to show exactly the point Appellöf was thinking of when he wrote this (sce p. 357), and it will be seen in general that if a spscies breeds at and above a certain temperature it must breed longer in general in a more southern or warmer locality of its distribution, sinco the sea-temperature in such situations will in general remain above that figure for a longer period.

Appellöf also states that Tapes decussatus, which is a species requiring greater warmth than generally prevails in the boreal region, occurs in isolated, shallow, sandy, open bays on the western coast of Norway from Bergen down to the south coast. These bays he found had sometimes a temperature of $23^{\circ}$ or $24^{\circ} \mathrm{C}$. in summer, and states that "Beyond question this high summer temperature, in combination with favourable bottom conditions and the salt water, enables Tapes decussatus to thrive and, what is more important, to reproduce itself."

Thus it is seen that no doubt can exist of the importance of temperature as a factor determining the distribution of marine animals, and one reason of this is now quite plain, namely, that different animals require definite temperatures for the purposes of reproduction.

* Tho italics are mine.

$\dagger$ A p.pcliö (l.c., p. 526-7) gives examples of animals whose vertical distribution may vary sj much as from two thousand metres to less than thirty metres, and states in effect that this phenomenon is not uncommon. 
Moreover, if temperature is of great importance for reproduction, then in general three conditions follow, namely :-

(1) Cosmopolitan forms should have a wide range of temperature for breeding.

(2) High latitude forms in relatively low latioude siouations should find their breeding period at least in relauively low temperatures for the locality.

(3) Low latitude forms in relatively high lacioudes should only breed in summer.

A few examples of each of these may be mentioned now. Ciona intestinalis, which has a very wide distribution (Har umeyer),* breeds all the year round at Naples (Lo Bianco, l.c.) and very nearly all the year at Plymouth. Balanus balanoides is an example of a high latitude form which breeds at Plymouth at and about the arrival of the minimum temperature. Styelopsis (Dendrodoa) grossularia is a member of a northern genus on the edge of its southern distribuivion* which breeds throughout most of the year at Plymouth; and the European oyster is an example of a low latitude form which in the more open oyster ponds of Norway, on the northern limit of its disiribution, only breeds in August or not at all (Helland-Hansen, 26), whilst in the Mare Piccolo, on the Gulf of Toranto, it breeds from April to October or longer (Bashford Dean, 29, p. 361).

These examples therefore show one way in which distribution may be limited by temperature conditions.

\section{ORIGINATION OF SPECIES BY VARIATION OF BREEDING TEMPERATURE CONSTANTS.}

Ió was originally intended to delay a consideration of the matter in this paragraph until a good number of cases were definitely and carefully correlated with breeding temperatures. Bưt as Appellöf has anticipated the concepurion to some extent, it can only do good to throw the subject open to discussion. Appellöf (l.c., p. 555) staites: "We have already seen that many species are common to bouth boreal and purely arctic areas, and we must ascribe their widespread distribution to their power of adapting themselves to very different temperatures. Most likely we are dealing here with physiologically distinct species, even though the differences do not appear in corresponding morphological alterations in bodily structure. Not that differences of this latter kind are by any means excluded, as I have previously shown how a species

* See O. Seeliger and R. Hartmeyer, Das Tier-Reich, H. G. Brsnn, Tunicata, Dritter Band, I Abteilung, pp. 1540 and 1529. Leipzig, 189-1911. 
may vary morphologically in certain directions, according as it occurs in arctic or boreal tracts. Future researches regarding the time when reproduction begins in these widespread forms in the respective areas will possibly show that the temperature at which development takes place varies a good deal less than the temperature prevailing in the different areas seems to indicate." It is a matter of common knowledge that it is towards the limit of the distribution of a species that it often becomes difficult to distinguish an animal from its allies. And, indeed, this is an important source of trouble in determining the synonymy of an animal for the purpose of obtaining its breeding periods at different regions of its distribution. Appellöf has perceived that its reaction to temperature is one character in which an animal may begin to vary or to take advantage of variations at the limit of its distribution. It is perfectly conceivable that an animal may increase its temperature range advantageously down or up beyond the normal death-temperature or growthtemperature for the species. Mayer (27) has, indeed, shown that this phenomenon of raising the death-temperature above the normal for the species occurs in Aurelia in the tropies. Thus may arise what Appellöf calls physiological species. Possibly his term for a variety of this kind is too strong, and the term sub-species or "race" might more correctly interpret this phase of adaptation. Appellöf's conception may, however, be carried further in the light of this research. At the limit of distribution of a species which is supposed to depend upon a certain definite temperature or definite temperature range for reproduction an opportunity arises for the species to utilise any variation in its metabolic processes which permits of its reproducing under conditions diff rent from those under which the parent stock exists. Variations of this kind might be immediately effective in extending the range of the stock. At first the new variety, sub-species or race might differ little from the parent stock, but the new influences to which it might bə subjected outside the experience of the parent stock would probably be reflected sooner or later in definite morphological changes, as indeed Appellöf has already shown. Now, it is a curious fact that two well-known species in the Mediterranean appear to exhibit features somewhat corresponding to those pictured here, namely,

\section{Ostrea edutis with varieties (?) plicata, depressa, cristata, falcata.}

\section{Mytilus edulis ,, ,, (?) gallo-provincialis.}

O. edulis is described by Faber $(28$, p. 17) as abounding in the Gulfs of Trieste and Venice, but only rarely in the Quarnero, where var. cristata is the only oyster found in certain parts. In the whole of the Adriatic Faber describes (l.c., p. 88) five different kinds of oysters, namely, "O. adriatica (Lam.), found generally on the limestone beds of the 
Adriatic, but neither in the lagoons nor in the oyster ponds; $O$. lamellosa (Brocchi) (Ostrica à lamelle), a species which is reared in ponds on a large scale, attains to large dimensions, and is the most savoury of the Adriatic species; three varieties of $O$. edulis (L.), viz. var. depressa (Phillipi) (Ostrica communa depressa, vulgo Ostrichino), a small species common to the lagoons and at Zaole, found attached to wood, and the mussels Pinna and Mytilus, and much liked on account of its savoury taste ; var. cristata (Auct. (?) Born. (?)) (Ostrica commune crestata), and var. falcata (Chiereghin) (Ostrica commune falcata), both found in the lagoons, ponds, harbours, on limestone and muddy beds. The former is the only kind which occurs in the Quarnero."

At Naples (Lo Bianco, l.c., p. 621) O. edulis occurs with a form described as O. plicata Chemn. (Osteco do Castrello), which occurs in shallower (and in summer hotter) water than $O$. edulis. Lo Bianco has obtained this form full of sexual products in May and July towards the hottest time of the year when very high temperatures may be expected in shallow water in this locality. Bashford Dean $(29$, p. 358$)$ states " that the gulfs of the north (of Italy) do not appear to be favourable to the growth of the typical European oyster, O. edulis. The Gulf of Genoa produces a small oyster mainly for local consumption, O. plicata (more probably 0 . edulis var. plicata), a species delicately flavoured and appearing to find its best living conditions in waters as dense as $1 \cdot 027$ to $1 \cdot 028$. In the harbours of Trieste and Venice another variety of oyster occurs, $O$. edulis venetiana. This is generally regarded as poorer in quality than edulis, and its production therefore competes but little with the southern industry."

It is therefore seen that in the Mediterranean, on the southern natural fringe of the distribution of $O$. edulis, great activity is occurring or has occurred in the production of varieties, and indications are given that these varieties are varying in the direction of reproducing under high temperature and high salinity conditions $(O$. plicata (?) (Dean and Lo Bianco, l.c.).

A thorough biological investigation of these Mediterranean oysters might therefore bring out facts of great value in the study of the mode of divergence of varieties from the parent stock. One of these forms, $O$. plicata or $O$. edulis var. plicata, appears to be a definite physiological variety or race of the kind expected by Appellöf and from the investigations described here.

A form of the genus Mytilus occurs in the Mediterranean and is identified by Lo Bianco (1.c., p. 620) as M. galloprovincialis ; but both Jeffreys $(30$, p. 105$)$ and Forbes and Hanley $(31$, p. 171) regard this form as a variety of Mytilus edulis. After describing this form as a separate species, Dautzenberg and H. Fischer have reuniced this form with the type under 
the species name Mytilus edulis (32, 1912, p. 361). As there are no anatomical features sufficiently developed to warrant the separation of these two forms, it would seem that it is in the direction of physiological characters, such as temperature conditions for reproduction and adaptability to different salinities and similar characters, that one must look for differences between the two forms. Thus in this species also some vague indication is given that an offshoot of the parent stock has become adapted to the relatively strange conditions in the Mediterranean Sea.

\section{PHYSIOLOGICAL CONSTANTS OF A SPECIES.}

In recognising temperature as a factor of paramount importance in determining the geographical distribution and breeding of marine animals, other conditions being suitable, it would appear that if sufficient information were available of the physiological or rather biological characters of a particular species, then one should be able to plot out on a map the limits of a region suitable for the habitat of that particular species, a region which should coincide with its geographical distribution. In this way information would be obtained of any other conditions limiting distribution, such as abnormal salinity conditions, lack of suitable food, depth and light, etc. The main characters, which would be important for this purpose, would appear to be included in the following list :-

Temperatures under normal salinity conditions.

(1) Upper death limit.

(2) Upper limit of growth or hibernation conditions.

(3) Maximum limit for breeding.

(4) Minimum limit for breeding.

(5) Lower limit of growth or hibernation conditions.

(6) Lower death point.

(7) Rate of change of temperature at different temperature levels causing death.

These characters would serve for probably all marine animals except littoral forms, and also as a guide for drawing up the more complicated tables which might be necessary for the latter.

\section{CONCLUSION.}

A review of all the information collected bearing on the influence of temperature changes on breeding leads one to the conclusion that a temperature stimulus of some kind is the normal impulse for inducing sexual activity in marine animals assuming normal biological conditions. In marine invertebrates, at least, the impression is gathered that normal 
salinity variations within the habitat of the species have little effect on breeding.

But an investigation of the conditions controlling breeding in a large number of species can only be satisfactorily made if breeding records are made in detail and the date and year mentioned and accompanied by reliable temperature and salinity observations for the habitat of the species. As it is now becoming the custom to connote all these data, there are good prospects of an important advance being made in the fucure in our knowledge of the conditions of life in the sea.

I am indebted to Dr. E. J. Allen for helpful criticisms, and the reader will already have learnt a small portion of my indebtedness to the writings of Prof. A. Appellöf and Dr. J. Hjort in the work on "The Depths of the Ocean," by Sir John Murray and Dr. Johan Hjort, a work which might very well be regarded as the marine biologist's vade-mecum.

\section{SUMMARY.}

The criterion of breeding is fertilisation resulting in subsequent development.

Experiments on rate of growth in marine invertebrates, carried out with the definite objects of obtaining information on (1) earliest age of maturity and (2) succession of seasonal growth, showed that in many animals tiny individuals are sexually mature at a very early age at a certain period of the year, whereas at other periods relatively large specimens of a greater age are not breeding.

These observations prove that food can be eliminated from the factors pre-eminently controlling breeding, and for reasons stuated it is considered highly probable that salinity variations can also be eliminated largely as a controlling influence under normal conditions.

Hence it was deduced that sea-temperature must be the influence of paramount importance controlling breeding in marine animals under normal biological conditions.

It was observed that breeding in the special instances investigated was continued throughout a period which extended between approximately homothermous epochs of the yearly sea-temperature variation. Hence it is deduced that breeding of this kind is dependent upon the attainment of a minimum breeding temperature of the medium.

Such a minimum breeding temperature would therefore appear to be a physiological constant for the species.

With a view to applying this deduction, the degree of correlation between the breeding period of the European oyster and temperature has been exhaustively examined and the conclusion arrived at that this molluse begins to spawn in a mean temperature of $15^{\circ}-16^{\circ} \mathrm{C}$. through- 
out its geographical range. Further, this species continues to produce mature sexual products so long as the temperature remains above this figure. Hence there is a longer breeding period in the more southern or warmer oyster beds than in the more northern or colder ones. These results will be published shortly.

The breeding phenomena of the mackerel (Scomber scomber) were also examined and the conclusion arrived at that this animal begins to spawn throughout its geographical range at temperatures round about $12^{\circ}-13^{\circ} \mathrm{C}$., so that in its more southern or warmer habitats spawning. begins earlier in the year than in its more northern or colder habitats.

It was found that there are in the literature some important observations and authoritative opinions on the paramount importance of temperature controlling breeding in particular marine animals.

A review of the breeding periods of marine animals at Naples (Lo Bianco), Plymouth ("Marine Invertebrate Fauna") and Millport (collected unpublished records) yielded much information in support of the deductions arrived at up to this time; but as a full consideration of all the facts will be a labour of years, an introductory study of them is all that is attempted here.

Temperature seems to influence breeding in marine animals in various ways which appear to be dependent upon the limitation of the breeding period by apparently constant maximum and/or minimum temperatures. These temperatures appear to be physiological constants for the species.

Hence in sedentary marine invertebrates the breeding period will depend, among other factors, upon the temperature range of the habitat and therefore mainly upon latitude. This phenomenon is well shown in the oyster, which breeds during seven months or more of the year in its more southern and warmer habitats, but during only one or two months or even not at all in some years in its more northern and colder ones.

Examples are given of breeding periods at Plymouth extending over a period of the year limited by homothermal epochs representing the minimum temperature for breeding in each species. There are examples in the breeding periods of animals at Naples of breeding in species being limited by approximately homothermal epochs representing the maximum temperatures for breeding in each species.

Perhaps the profoundest influence of temperature is at the minimum or the maximum temperature attained for a particular locality, and there are examples in the breeding records of

(1) many breeding periods beginning at or very close upon the minimum temperature for the locality, a type of breeding to which it will probably be found that a good many fishes conform, and 
(2) other breeding periods beginning at or very close upon the maximum temperature for the locality.

Breeding periods must be also studied in the light of rate of growth of the species, method of spawning and habits.

Hibernation phenomena in some marine animals are shown to be controlled probably by definite temperatures and to resemble the breeding phenomena described. Many examples are given of tiny young animals being sexually mature at an early age when born into temperature conditions suitable for breeding, and the similarity of these conditions to those obtaining in the tropies is pointed out.

Pre-breeding influences are reviewed briefly.

The relation between breeding and growth, as manifested by the material obtained by experiment, is discussed shortly, and it is shown that size and age at maturity are directly dependent upon temperature. It would also appear that the dimensions of some species in a given locality are dependent, other things being equal, on the relative lengths of the breeding period and the non-breeding period; consequently it is to be expected that in different localities, or in different seasons, comparative size - other things being ihe same - will depend upon the relative length of these periods.

The breeding of marine animals under constant temperature conditions is discussed, for it would appear that if temperature is of paramount importance in controlling breeding periods, breeding should be continuous in homothermal regions under normal biological conditions.

In the stenothermal conditions of the tropics there is apparently good evidence that breeding in marine animals is continuous, but a thorough investigation of this problem is desirable. The breeding conditions of the deep-sea fauna at all periods of the year are not well known, and attention is directed to the importance of recording the sexual conditions of this community. But it is pointed out that the minute sexually mature deep-sea fishes resemble the phenomena of many tiny young invertebrates, which also become sexually mature when born into suitable breeding conditions. There are indications in the literature that breeding may be continuous in the polar regions in their respective summers, but the problem is here complicated by the abnormal seasonal biological conditions and the lack of information on the rate of growth of marine animals in the polar regions.

Since temperature is known to be of paramount importance in controlling distribution, it would seem that its influence on breeding is one of the ways in which the controlling effect is exerted. It is also suggested that divergences from the breeding-temperature constants especially at the limits of the geographical distribution of a species-may be one 
method of origin of physiological sub-species or varieties, and the examples of the oyster and the mussel in the Mediterranean Sea are shorily discussed, and the nature of the information required in these problems is outlined.

This suggestion has been in part anticipated by Appellöf.

An investigation of the physical conditions in many estuaries and in littoral situations, and the connotation of the year with the date on which breeding observations are made, would give valuable help in further investigations on the influence of physical conditions on breeding in marine animals, and thus materally assist in the solution of many problems of the life in the sea.

\section{REFERENCES.}

1. S. Lo Bianco. Notizie biologiche reguardanti specialmente il periodo di maturà sessuale degli animali del golfo di Napoli. Mitt. aus der Zool. Station zu Neapel. 19 Band 4 heft. 1909.

2. Johs Schmidt. The Distribution of the Pelagic Fry and Spawning Regions of the Gadoids in the North Atlantic from Iceland to Spain. Conseil Permanent International pour l'Exploration de la Mer. Rapports et Procés-Verbaux, Vol. X. Period 1902-07 (1909). Copenhagen.

3. J. H. Orton. Preliminary Account of a Contribution to an Evaluation of the Sea. Journ. Mar. Biol. Assoc., Vol. X, No. 2, 1914, p. 312 .

4. A. Dendy. Observations on the Gametogenesis of Grantia compressa. Quart. Journ. Micr. Sci., Vol. 60, 1915, p. 313. (See p. 322.)

5a. H. R. Mill. On the Temperature of the Water in the Firth of Forth. Proc. Roy. Soc. Edin., Vol. XIII, 1884-86, p. 347.

5b. - On the Salinity of the Water in the Firth of Forth. Proc. Roy. Soc. Edin., Vol. XIII, 1884-86, p. 29.

6a. H. N. Dickson. The Movements of the Surface Waters of the North Sea. The Geographical Journal, March, 1896.

6b. _ - The Mean Temperature of the Surface Wavers of the Sea round the British Coasts, and its Relation to the Mean Temperature of the Air. Quart. Journ. Roy. Meteorological Soc., Vol. XXV, No. 112, Oct., 1899. Table V, p. 299.

7. G. Karsten. Die Physikalischen Beobachtungen an der Stationen. Wissenschaften Meeresuntersuchungen. Helgoland. Kiel.-I.1896. Hef ̈ 2, p. 145.

8. H. A. Meyer. Periodische Schwankungen des Saltzgehalten im oberflaschenwassers in der Ostsee und Nordsee. Untersuchungen d r Deứschen Meere, 1877-81, VII-XI. Taf I and II. Berlin, 1884. 
9. E. J. Allen. Report on the Present State of Knowledge with Regard to the Habits and Migrations of the Mackerel (Scomber scomber). Journ. Mar. Biol. Assoc., Vol. V, 1897-99.

10. D. Nitsson. A Contribution to the Biology of the Mackerel. Publ. de Circonstance, No. 69, p. 47. Copenhagen, 1914.

11. G. O. Sars. Description of Paracartia Grani. Bergens Museum, Aarbog, 1904, No. 4, pp. 1-16.

12. H. Friele. The Oyster Ponds of the Coast of Norway. Beretning om den Internationale Fiskerikongres, 1898. Selskabet for de Norske Fiskeriers Fremme. Bergen, 1899, p. 188.

13. A. Appellöf. Invertebrate Bottom Fauna of the Norwegian Sea and North Atlantic. The Depths of the Ocean. By Murray and Hjort. London, 1912.

14. K. Semper. Animal Life. Inter. Sci. Series. London, 1883, p. 428 .

15. A. Dendy and H. D. Elkington. Report on the Vitality and Rate of Multiplication of certain Insects under various conditions of Temperature and Moisture. Reports of the Grain Pestis (War) Committee, No. 7, p. 50. Royal Society, London, 1920.

16. Plymouth Marine Invertebrate Fauna. Journ. Mar. Biol. Assoc., Vol. VII, Dec., 1904.

17. J. H. Orton. Sex-phenomena in the Common Limpet (Patella vulgata). Nature, Dec. 11, 1919, No. 2615, Vol. 104, p. 373.

18. P. P. C. Hoek. Les organes de la génération de l'huî́re. Conưributions à la connaissance de leur structure ét de leurs fonctions. Tijdrschr. Nederlandsch Dierkundige Ver. Suppl., Deel I. Leiden, 1883-84, p. 113.

19. Bricish Meteorological and Magnetic Year Book, 1918, Part II. The Monthly Weather Report for the Year 1918. M.O. 231h. London, 1919, p. xiii.

20. E. C. Jee. Hydrography of the English Channel. Fishery Investigations Series III, Vol. I, Part I, p. 11 and p. 73. Board of Agriculture and Fisheries, London, 1919.

21. Monthly Normals of Temperature, Rainfall and Sunshine. British Meteorological and Magnetic Year Book, 1913, Part I (Weekly Weather Report), Appendix IV. M.O. 214a (1915).

22. D. J. Matthews. On the Amount of Phosphoric Acid in the Seawater off Plymouth Sound. Journ. Mar. Biol. Assoc., Vol. XI, No. 1, p. 128.

23. B. Helland-Hansen and F. Nansen. Temperatur-Schwankungen des Nordatlantischen Ozeans und in der Atmosphäre. Videnskapsselskapets Skrifter. I. Nat.-naturv. Klasse, 1916, No. 9. Kristiania, 1917. 
24. J. Hornell. The Biological Results of the Ceylon Pearl Fishery of 1904. Reports from the Ceylon Biol. Laboratory, No. 1, 1905, p. 8.

25. J. Hjort. Chapter on General Biology. Depths of the Ocean. Sir J. Murray and J. Hjort. London, 1912.

26. B. Helland-Hansen. Die Austerbassins in Norwegen. Internat. Revue Hydrobiol. Hydrograph. I, 1908, p. 571.

27. A. G. Mayer. Effects of Temperature on Tropical Marine Animals. Publ. No. 183 Carnegie Inst., Washington, 1914, pp. 1-24.

28. G. L. Faber. The Fisheries of the Adriatic. Quaritch, London, 1883.

29. Bashford Dean. Report on the European Methods of OysterCulture. Bulletin of the United States Fish Commission, Vol. XI, 1891.

30. J. C. Jeffreys. British Conchology, Vol. II. London, 1863.

31. E. Forbes and S. Hanley. British Mollusca, Vol. II, p. 195.

32. Ph. Dautzenberg and H. Fischer. Mollusques. Campagne de l'Hirondelle ế de la Princesse-Alice. Rés. Campagnes Sci., Fasc. XXXVII. Monaco, 1912, p. 361-2. 